\title{
RECONSTRUCTION OF TEMPERATURE FOR THE PAST 400 YEARS IN THE SOUTHERN MARGIN OF THE TAKLIMAKAN DESERT BASED ON CARBON ISOTOPE FRACTIONATION OF TAMARIX LEAVES
}

\author{
ZHANG, Z. ${ }^{1}-$ Ullah, I. ${ }^{1}-$ WANG, Z. ${ }^{1}-$ MA, P. ${ }^{1}-$ ZHAO, Y $.^{1 *}-$ XIA, X. ${ }^{2}-$ LI, Y. ${ }^{3}$ \\ ${ }^{1}$ Hebei Key Laboratory of Environmental Change and Ecological Construction, College of \\ Resources and Environmental Sciences, Hebei Normal University, Shijiazhuang 050024, China \\ ${ }^{2}$ Xinjiang Institute of Ecology and Geography, Chinese Academy of Sciences \\ Urumqi 830011, China \\ ${ }^{3}$ Department of Geography, University of Tennessee, Knoxville, TN 37996, USA \\ *Corresponding author \\ e-mail: ecoenvir@163.com
}

(Received 15 $5^{\text {th }}$ Jun 2018; accepted $2^{\text {nd }}$ Aug 2018)

\begin{abstract}
Carbon isotope fractionation is sensitive to the environment factors associated with plant growth; thus, it can be used as a proxy to reconstruct past climate and environmental conditions. We investigated the relationship between carbon isotope signatures $\left(\delta^{13} \mathrm{C}\right)$ and its fractionation $\left(\Delta \delta^{13} \mathrm{C}\right)$ of Tamarix leaves and a set of climate and environmental factors in the Southern Margin of the Taklimakan Desert (SMTD). A principal component analysis was used to condense these factors as the temperature-, wind-, precipitation-, and humidity-related index, explaining $51.0 \%, 18.0 \%, 5.1 \%$, and $4.7 \%$ of the total variance, respectively. Combined with the correlation results, temperature is identified as the key growth-limiting factor for Tamarix in the SMTD. Specifically, $\delta^{13} \mathrm{C}$ has a statistically significant correlation with the lowest temperature in June $\left(\mathrm{LT}_{\mathrm{Jun}}\right)(r=0.717, p=0.000)$, and $\Delta \delta^{13} \mathrm{C}$ has a statistically significant correlation with the annual mean of the highest temperature (AMHT) $(r=0.700, p=0.000)$. Based on these high correlations, we reconstructed the $\mathrm{LT}_{\text {Jun }}$ and AMHT records in the past 400 years using $\delta^{13} \mathrm{C}$ and $\Delta \delta^{13} \mathrm{C}$ of Tamarix leaves deposited in the Tamarix cone. These records revealed a long-term fluctuation in temperature that can be divided into four sub-periods, including the history cold period (1600-1685), history warm period (1686 - 1913), modern cold period (1914-1993), and modern warm period (1994-2010). These records provide useful insight into the paleoclimate and environmental change in this arid region.
\end{abstract}

Keywords: climate change, environment, key growth-limiting factor

\section{Introduction}

Climate and environmental change affect plant carbon isotope signatures $\left(\delta^{13} \mathrm{C}\right)($ Seibt et al., 2008), and the carbon isotope fractionation $\left(\Delta \delta^{13} \mathrm{C}\right)$ is mainly related to the key limiting factors for plant growth (Xu et al., 2015). Temperature and precipitation are the two major growth-limiting factors for the changes in plant carbon isotope signature and fractionation, by affecting its stomata conductance and assimilation rate and altering C:N allocation to carboxylation and leaf structure (Seibt et al., 2008; Liu et al., 2014b). Consequently, $\delta^{13} \mathrm{C}$ and $\Delta \delta^{13} \mathrm{C}$ can be treated as measures of temperature and precipitation (Saurer et al., 1995; Loader et al., 2007; Dodd et al., 2008; Diefendorf et al., 2010), and used as proxies to reconstruct past climate conditions (Dawson and Siegwolf, 2007; Werner et al., 2012). Studies have indicated that precipitation has a negative influence on plant $\delta^{13} \mathrm{C}$ and a positive influence on $\Delta \delta^{13} \mathrm{C}$ (Farquhar et al., 1982; Wang et al., 2003, 2008; Kohn, 2010; Ren et al., 2011). However, the influence of temperature on plant $\delta^{13} \mathrm{C}$ 
is still unclear (Körner et al., 1988, 1991; Morecroft and Woodward, 1996; Wang et al., 2008, 2013; Gebrekirstos et al., 2009; Diefendorf et al., 2010; Kohn, 2010). This uncertainty is caused by difference of the key growth-limiting factors that affect on plant growth in different regions. The key growth-limiting factors of Tamarix growth have been statistically identified in the Southern Margin of the Taklimakan Desert (SMTD), and then the paleoclimate condition is reconstructed based on the relationship between the key growth-limiting factors and meteorological factors.

The Taklimakan Desert is the second largest desert in the world surrounded by the Tianshan Mountain in the north, the Aljin Mountain in the southeast, the Kunlun Mountain in the south, and the Pamir Plateau in the west. It is one of the most arid regions in the world because the high mountains and plateau block the water moist from the Atlantic and Indian oceans. The SMTD is one of the most fragile ecological environment areas in China. Tamarix is the major vegetation outside of the oasis that can survive the extremely arid climate in this area. Tamarix is mainly distributed on riverbanks, abandoned river channels, and the interlaced zone between desert and oasis. The interaction between wind sand and Tamarix forms the Tamarix cone, a unique biogeomorphic landform, composing of alternate layers of sand and Tamarix twigs and leaves (Xia et al., 2004). Detailed climate records have been derived in this desert area using stable carbon isotope $\left(\delta^{13} \mathrm{C}\right)$ and its fractionation $\left(\Delta \delta^{13} \mathrm{C}\right)$ of Tamarix leaves from different layers of the Tamarix cones (Zhao et al., 2011a, b, 2015a, b, 2016; Zhao, 2012; Sun, 2013; Sun et al., 2013; Guo et al., 2016; Zhang et al., 2017).

In the work reported here, the relationship between carbon isotope $\left(\delta^{13} \mathrm{C}\right)$ and its fractionation $\left(\Delta \delta^{13} C\right)$ signatures and various observed climate factors (1960-2010) were investigated to identify the key growth-limiting factor of Tamarix growth. Base on the relationship, the lowest temperature in June ( $\mathrm{LT}_{\mathrm{Jun}}$ ) and the annual mean of highest temperature (AMHT) of the past 400 years were reconstructed in the SMTD. This study provides useful insight into the relationship between plant $\delta^{13} \mathrm{C}, \Delta \delta^{13} \mathrm{C}$ signatures and climate variables and use $\delta^{13} \mathrm{C}$ and $\Delta \delta^{13} \mathrm{C}$ as proxies to reconstruct paleo-climate and environmental change in arid regions.

\section{Study area}

This study was conducted in Andier Meadow $\left(83.82^{\circ} \mathrm{E}, 37.72^{\circ} \mathrm{N}\right)$, far from the Minfeng oasis, which belongs to the Hotian Prefecture in the SMTD of Xinjiang Uygur Autonomous Region, China (Fig. 1). The sampling site is located on the edge of the alluvial fan formed by the Andier River, representing a transition zone between the Taklimakan Desert and Kunlun Mountains. This area belongs to the temperate continental and arid desert climate zone. According to the observed data from the Minfeng meteorological station, the mean of annual temperatures is $11.19{ }^{\circ} \mathrm{C}$ and relatively constant over the years. The average annual precipitation is $29.4 \mathrm{~mm}$ with a relatively large range between 4.0 and $136.9 \mathrm{~mm}$. About $85.4 \%$ of the precipitation falls from May to September. The annual average evaporation can reach to $2756 \mathrm{~mm}$.

\section{Data and methods}

To minimize the influence of human activity, we investigated a Tamarix cone in Andier meadow, more than $100 \mathrm{~km}$ away from the Minfeng oasis. We collected the samples layer by layer from top to bottom from June 18th to 20th in 2011. The samples 


$$
-273-
$$

were collected based on the average thickness when the sedimentary veins are not clear. In total, we collected 106 samples. The freshest leaves of the top layer were dated in 2010 .

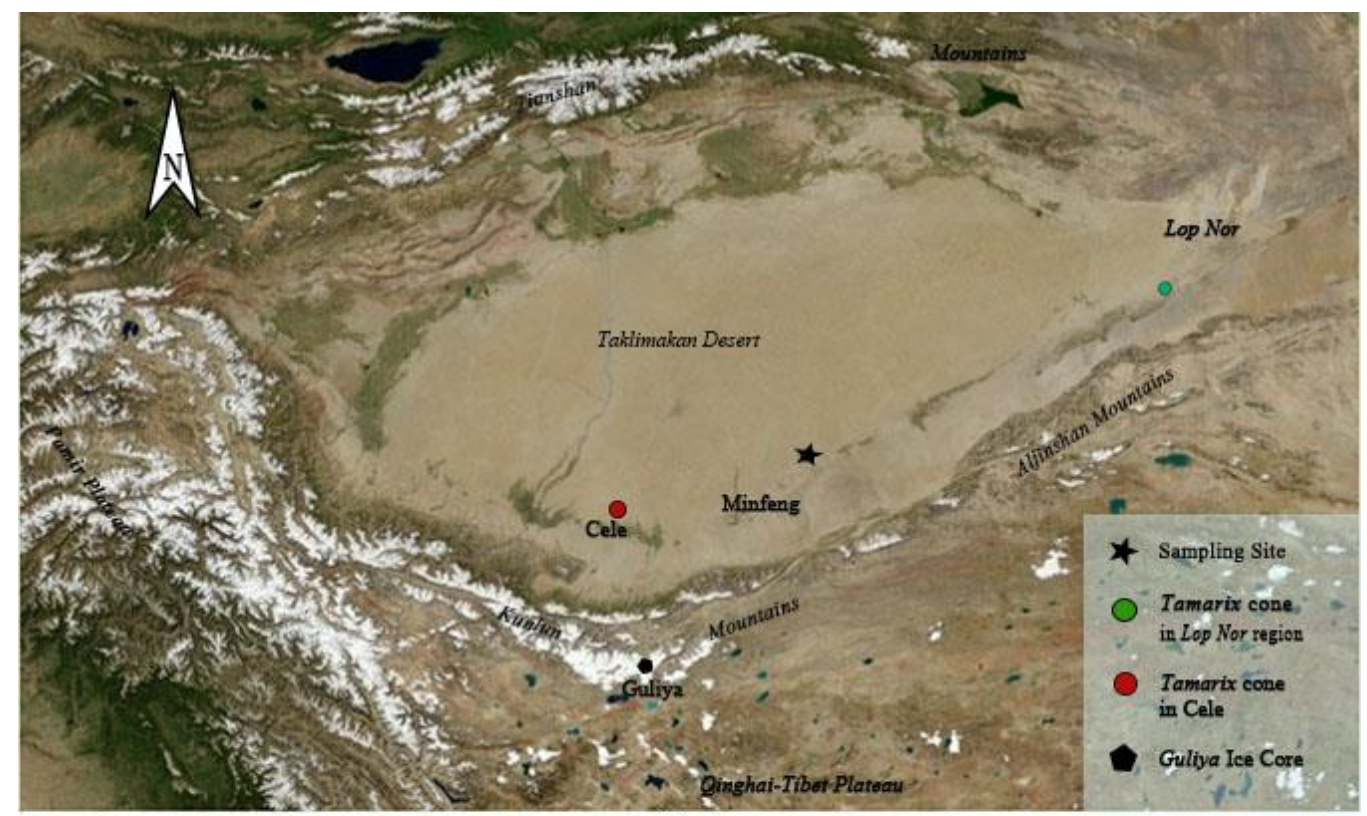

(a)

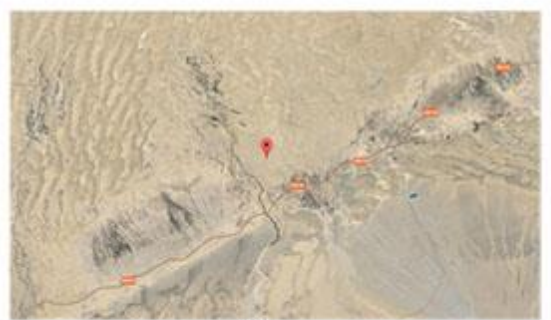

(b)

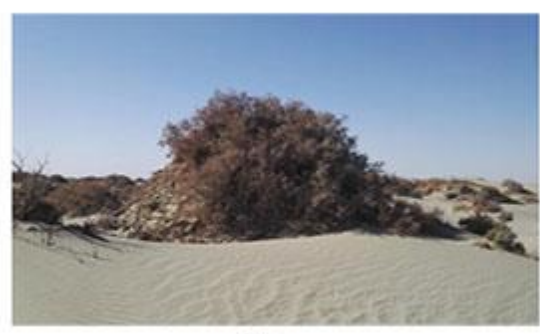

(c)

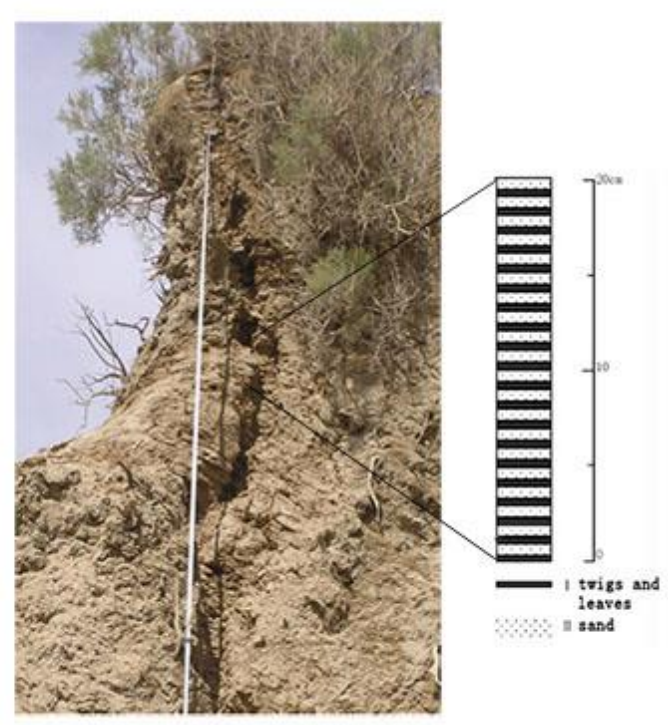

(d)

Figure 1. Location of sampling site in Andier meadow of Minfeng County $(a, b)$; a typical Tamarix cone (c); a sampling profile of Tamarix cone $(d)$

All samples were pretreated by washing, stoving, grinding, and packing in penetrative bag in the Key Laboratory of Environmental Change and Ecological Construction, Hebei Normal University. The $\delta^{13} \mathrm{C}$ value of each sample was measured in the Nanjing Institute of Geography and Limnology, Chinese Academy of Sciences, based on the Vienna Pee Dee Belemnite (VPDB) standard (the standard error of $0.1 \%$ ). Both ${ }^{210} \mathrm{~Pb}$ and ${ }^{137} \mathrm{Cs}$ were measured to constrain the age sequence, combined with ${ }^{14} \mathrm{C}$ 
dating by the Accelerator Mass Spectrometry Laboratory in Beijing University (Zhao et al., 2015b).

The carbon isotope fractionation $\left(\Delta \delta^{13} \mathrm{C}\right)$ of Tamarix leaves is derived by the following formula (Eq. 1; Farquhar et al., 1984, 1989):

$$
\Delta \delta^{13} C=\frac{\delta^{13} C_{a}-\delta^{13} C_{t}}{1+\delta^{13} C_{t} / 1000} \approx \delta^{13} C_{a}-\delta^{13} C_{t}
$$

Where $\delta^{13} \mathrm{C}_{\mathrm{a}}$ represents the carbon isotope ratio in atmosphere measured from ice core bubbles or plant $\delta^{13} \mathrm{C}$ value (Friedli et al., 1986; Leavitt and Long, 1989; Mccarroll and Loader, 2004); $\delta^{13} \mathrm{C}_{\mathrm{t}}$ represents the carbon isotope ratio of Tamarix leaves.

The climate data were obtained from the Mingfeng meteorological station, close to the sampling site. The data include the monthly and yearly lowest, highest and mean temperature, sunshine duration, precipitation, relative humidity, wind speed, windy days, and sand storms during 1960-2010. These data are divided into three categories: temperature-related, water-related, and wind-related variables.

We first explored the descriptive statistics of $\delta^{13} \mathrm{C}$ and $\Delta \delta^{13} \mathrm{C}$ and then performed bivariate correlation analyses between $\delta^{13} \mathrm{C}, \Delta \delta^{13} \mathrm{C}$ and the temperature-related, waterrelated, wind-related variables. Due to the large number of the variables and their intercorrelations, we applied the principal component analysis to condense the variables into several major components and determine the contributions of different variables to $\delta^{13} \mathrm{C}$ and $\Delta \delta^{13} \mathrm{C}$. The key growth-limiting factors for Tamarix were then determined based on their correlations and contributions. We applied the least square regression to establish the relationship between $\delta^{13} \mathrm{C}$ and $\Delta \delta^{13} \mathrm{C}$ and the key growth-limiting factors and use this relationship to reconstruct the variations of these factors in the past. Most of the statistical analyses were performed using IBM SPSS Statistics. The regression was carried out by software, EViews.

\section{Results}

\section{$\delta^{13} C$ and $\Delta \delta^{13} C$ variations}

Based on the chronology established by Zhao et al. (2015b) using ${ }^{14} \mathrm{C},{ }^{210} \mathrm{~Pb}$ and ${ }^{137} \mathrm{Cs}$ dating, we illustrated $\delta^{13} \mathrm{C}$ and $\Delta \delta^{13} \mathrm{C}$ variations for the Minfeng sampling site in the past 400 years (Fig. 2). The $\delta^{13} \mathrm{C}$ values vary from $-26.979 \%$ to $-22.149 \%$, and the $\Delta \delta^{13} \mathrm{C}$ values fluctuate between $15.397 \%$ and $20.265 \%$ with a mean of $18.009 \%$.

\section{Correlation analysis}

We analyzed the correlations between temperature-related variables, including the monthly highest temperature, monthly lowest temperature, monthly mean temperature, annual mean of highest temperatures, annual mean of lowest temperatures, annual mean temperature, monthly sunshine hours and annual cumulative sunshine hours, and $\delta^{13} \mathrm{C}$, $\Delta \delta^{13} \mathrm{C}$. At the $95 \%$ confidence level, the significantly related variables were selected and listed in Table 1.

The correlations between $\delta^{13} \mathrm{C}, \Delta \delta^{13} \mathrm{C}$ and the water-related variables, such as the monthly precipitation, annual precipitation, monthly mean of air relative humidity, annual mean of air relative humidity, showed that statistically significant correlations ( $\mathrm{P}$ $<0.05)$ only occur in January $(r=-0.417, p=0.038)$ between $\delta^{13} \mathrm{C}$ and precipitation, 
and in June $(r=0.401, p=0.047)$ and November $(r=0.534, p=0.006)$ between $\delta^{13} \mathrm{C}$ and air relative humidity. Statistically significant correlations occur in April $(r=0.445$, $p=0.026)$ between $\Delta \delta^{13} \mathrm{C}$ and precipitation, and in November $(r=-0.579, p=0.002)$ between $\Delta \delta^{13} \mathrm{C}$ and air relative humidity only.

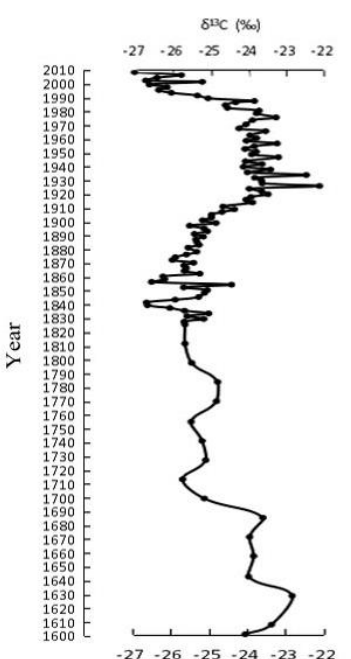

(a)

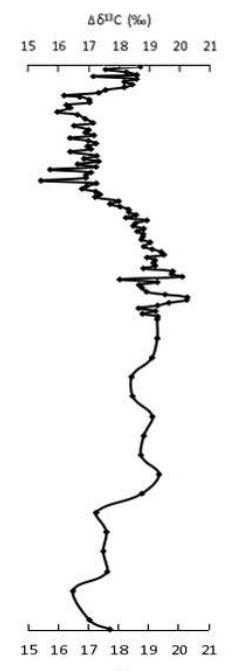

(b)

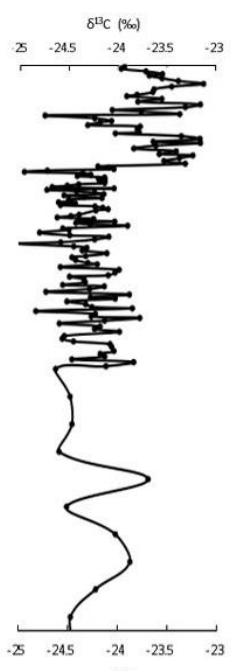

(c)

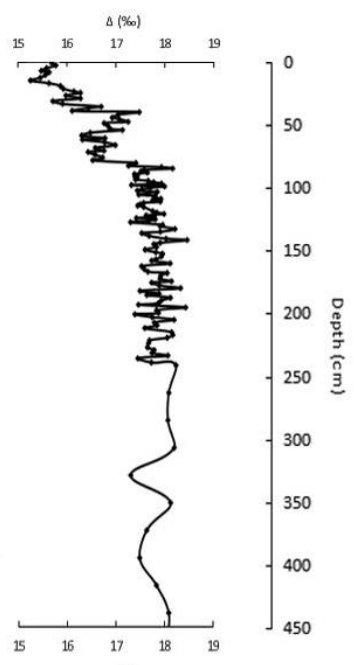

(d)

Figure 2. The age sequence of $\delta^{13} C$ in Minfeng sampling site (a); the age sequence of $\Delta \delta^{13} C$ in Minfeng sampling site (b); the age sequence of $\delta^{13} C$ in Cele (Zhang et al., 2017) (c); the age sequence of $\Delta \delta^{13} C$ in Cele (Zhang et al., 2017) (d)

Table 1. Pearson correlations ( $r$ ) of temperature-related variables with $\delta^{13} \mathrm{C}, \Delta \delta^{13} \mathrm{C}$

\begin{tabular}{c|c|c|c|c}
\hline \multirow{2}{*}{ Lowest Temperature } & \multicolumn{2}{|c|}{$\boldsymbol{\delta}^{\mathbf{1 3}} \mathbf{C}$} & \multicolumn{2}{c}{$\Delta \boldsymbol{\delta}^{\mathbf{1 3}} \mathbf{C}$} \\
\cline { 2 - 5 } & $\boldsymbol{r}$ & $\boldsymbol{p}$ & $\boldsymbol{p}$ \\
\hline Lowest temperature in Jan & -0.557 & 0.004 & 0.564 & 0.003 \\
Lowest temperature in Feb & -0.546 & 0.005 & 0.575 & 0.003 \\
Lowest temperature in Mar & -0.537 & 0.006 & 0.586 & 0.002 \\
Lowest temperature in Apr & -0.509 & 0.009 & 0.530 & 0.006 \\
Lowest temperature in May & -0.511 & 0.009 & 0.452 & 0.023 \\
Lowest temperature in Jun & -0.717 & 0.000 & 0.626 & 0.001 \\
Lowest temperature in Jul & -0.602 & 0.001 & 0.616 & 0.001 \\
Lowest temperature in Aug & -0.491 & 0.013 & 0.497 & 0.011 \\
Lowest temperature in Sep & -0.553 & 0.004 & 0.566 & 0.003 \\
Lowest temperature in Oct & -0.557 & 0.004 & 0.489 & 0.013 \\
Lowest temperature in Nov & -0.612 & 0.001 & 0.526 & 0.007 \\
Lowest temperature in Dec & -0.586 & 0.002 & 0.495 & 0.012 \\
Annual mean of lowest temperatures & -0.665 & 0.000 & 0.639 & 0.001 \\
Annual mean of highest temperatures & -0.608 & 0.001 & 0.700 & 0.000 \\
Annual mean temperature & -0.694 & 0.000 & 0.671 & 0.000 \\
\hline
\end{tabular}

The correlations between $\delta^{13} \mathrm{C}, \Delta \delta^{13} \mathrm{C}$ and the wind-related variables, such as monthly mean wind speed, annual mean wind speed, monthly windy days, annual 


$$
-276-
$$

windy days, monthly sand-blowing days, annual sand-blowing days and sandstorm days, were analyzed, and the significantly related variables $(\mathrm{P}<0.05)$ were selected and listed in Table 2.

Table 2. Pearson correlations ( $r$ ) of wind-related variables with $\delta^{13} C, \Delta \delta^{13} C$

\begin{tabular}{c|c|c|c|c}
\hline & \multicolumn{2}{|c|}{$\boldsymbol{\Delta}^{\mathbf{1 3}} \mathbf{c}$} & \multicolumn{2}{c}{$\boldsymbol{\Delta}^{\mathbf{1 3}} \mathbf{C}$} \\
\hline & $\mathbf{R}$ & $\mathbf{P}$ & $\mathbf{R}$ & $\mathbf{P}$ \\
\hline Wind speed in Feb & & & -0.495 & 0.012 \\
Wind speed in Mar & 0.408 & 0.043 & -0.503 & 0.010 \\
Wind speed in Apr & & & -0.494 & 0.012 \\
Wind speed in May & & & -0.412 & 0.041 \\
Wind speed in Jul & & & -0.415 & 0.039 \\
Wind speed in Aug & 0.433 & 0.031 & -0.415 & 0.039 \\
Wind speed in Sept & 0.656 & 0.000 & -0.629 & 0.001 \\
Wind speed in Oct & 0.528 & 0.007 & -0.593 & 0.002 \\
Annual wind speed & 0.596 & 0.002 & -0.622 & 0.001 \\
\hline
\end{tabular}

\section{Principal component analysis}

Principal component analysis (PCA) carried on the 26 variables related to $\Delta \delta^{13} \mathrm{C}$ for data compression. The KMO (Kaiser-Meyer-Olkin) value (0.496) is poor, however Bartlett's test of sphericity $(\mathrm{P}<0.001)$ indicates we can proceed. Based on the rule that the minimum eigenvalue should not be less than 1 , four components were extracted from the PCA result (Table 3). Eliminating the coefficient less than 0.5, the factor loadings are showed in the rotated component matrix (Table 4).

Table 3. Total variance explained

\begin{tabular}{c|c|c|c|c|c}
\hline \multicolumn{2}{c|}{ Component } & $\mathbf{1}$ & $\mathbf{2}$ & $\mathbf{3}$ & $\mathbf{4}$ \\
\hline \multirow{3}{*}{ Initial eigenvalues } & Total & 13.258 & 4.671 & 1.327 & 1.223 \\
& \% of variance & 50.994 & 17.965 & 5.103 & 4.704 \\
& Cumulative \% & 50.994 & 68.959 & 74.062 & 78.766 \\
\hline \multirow{2}{*}{ Extraction sums of squared } & Total & 13.258 & 4.671 & 1.327 & 1.223 \\
loadings & \% of variance & 50.994 & 17.965 & 5.103 & 4.704 \\
& Cumulative \% & 50.994 & 68.959 & 74.062 & 78.766 \\
\hline \multirow{3}{*}{ Rotation sums of squared loadings } & Total & 10.639 & 7.051 & 1.527 & 1.261 \\
& \% of variance & 40.921 & 27.120 & 5.875 & 4.850 \\
& Cumulative \% & 40.921 & 68.041 & 73.916 & 78.766 \\
\hline
\end{tabular}

\section{Regression analysis}

Liner regression analyses were performed to explore the relationship between temperature and $\delta^{13} \mathrm{C}, \Delta \delta^{13} \mathrm{C}$, and then regression models were built to reconstruct the paleotemperature. Firstly, based on the correlation $(\mathrm{r}=0.72, \mathrm{P}=0.00)$ between $\delta^{13} \mathrm{C}$ values and the observed lowest temperature in June (LT $\mathrm{Lun}_{\mathrm{Jun}}$, the reconstruction model of $\mathrm{LT}_{\text {Jun }}$ is $(E q .2)$ : 


$$
-277 \text { - }
$$

$$
\begin{array}{ccc}
L T_{\text {Jun }}= & -9.542-1.031 * \delta^{13} C \\
\text { Std.Error } & 5.183 & 0.209 \\
P \text {-value } & 0.079 & 0.000
\end{array}
$$

The $\mathrm{R}^{2}$ of the model is 0.51 . We used this equation to reconstruct the $\mathrm{LT}_{\mathrm{Jun}}$. Figure $3 a$ illustrates the reconstructed lowest temperature in June, and Figure $3 b$ shows

\begin{tabular}{|c|c|c|c|c|}
\hline & \multicolumn{4}{|c|}{ Component } \\
\hline & 1 & 2 & 3 & 4 \\
\hline Lowest temperature in Jan & 0.826 & & & \\
\hline Lowest temperature in Feb & 0.797 & & & \\
\hline Lowest temperature in Mar & 0.720 & & & \\
\hline Lowest temperature in Apr & 0.750 & & & \\
\hline Lowest temperature in May & 0.636 & & & \\
\hline Lowest temperature in Jun & 0.795 & & & \\
\hline Lowest temperature in Jul & 0.682 & & & \\
\hline Lowest temperature in Aug & 0.820 & & & \\
\hline Lowest temperature in Sep & 0.873 & & & \\
\hline Lowest temperature in Oct & 0.882 & & & \\
\hline Lowest temperature in Nov & 0.913 & & & \\
\hline Lowest temperature in Dec & 0.875 & & & \\
\hline Annual mean of lowest temperature & 0.967 & & & \\
\hline Annual mean of highest temperature & 0.519 & & & \\
\hline Annual mean temperature & 0.868 & & & \\
\hline Mean winds peed & & 0.880 & & \\
\hline Wind speed in Feb & & 0.899 & & \\
\hline Wind speed in Mar & & 0.904 & & \\
\hline Wind speed in Apr & & 0.866 & & \\
\hline Wind speed in May & & 0.936 & & \\
\hline Wind speed in Jul & & 0.929 & & \\
\hline Wind speed in Aug & & 0.656 & & \\
\hline Wind speed in Sept & & 0.685 & & \\
\hline Wind speed in Oct & & 0.736 & & \\
\hline Precipitation in Apr & & & & 0.847 \\
\hline Air relative humidity in Nov & & & -0.726 & \\
\hline Lowest temperature in Jan & 0.826 & & & \\
\hline Lowest temperature in $\mathrm{Feb}$ & 0.797 & & & \\
\hline Lowest temperature in Mar & 0.720 & & & \\
\hline Lowest temperature in Apr & 0.750 & & & \\
\hline
\end{tabular}
the comparison between the reconstructed lowest temperature with the observed data from the Minfeng meteorological station.

Table 4. Rotated component matrix ${ }^{a}$

* a. 4 components extracted.

Secondly, based on the highest correlation coefficient $(\mathrm{r}=0.70, \mathrm{P}=0.00)$ between $\Delta \delta^{13} \mathrm{C}$ and the Annual Mean of Highest Temperature (AMHT), which is the highest one 
among all temperature-related variables, the relationship between $\Delta \delta^{13} \mathrm{C}$ and AMHT is (Eq. 3):

$$
\begin{array}{lll}
\text { AMHT }= & 10.274+ & 0.556 * \Delta \delta^{13} C \\
\text { Std.error } & 2.041 & 0.118 \\
P-\text { value } & 0.000 & 0.000
\end{array}
$$

The R-squared of the model is 0.49. Therefore, we selected AMHT as the representative temperature indicators for the past climate reconstruction. The reconstructed AMHT shows in Figure 3c, the reconstructed data compared with the observed data at Minfeng meteorological station is shown in Figure $3 d$.
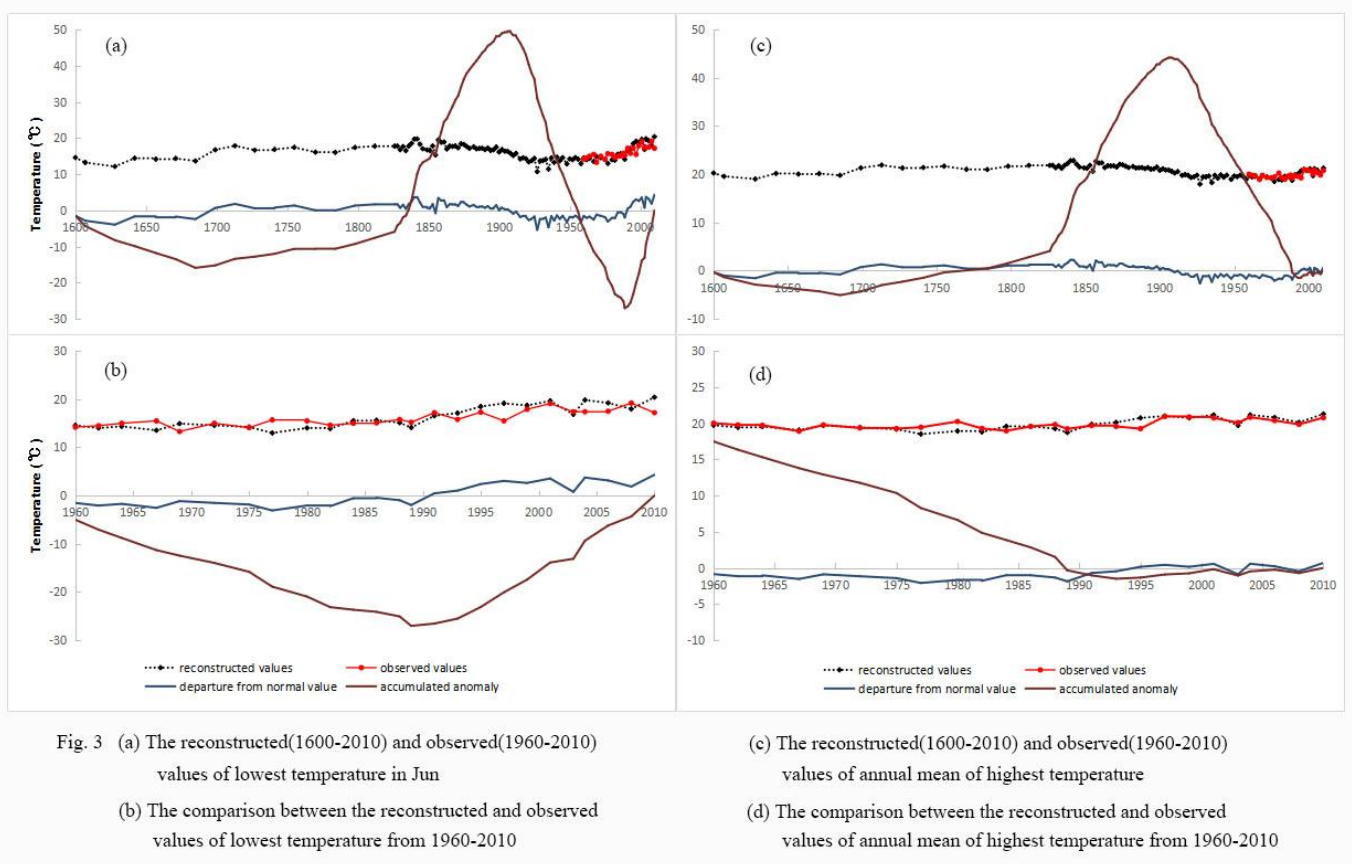

Figure 3. The reconstructed (1600-2010) and observed (1960-2010) values of lowest temperature in Jun (a); the comparison between the reconstructed and observed values of lowest temperature from 1960-2010 (b); the reconstructed (1600-2010) and observed (1960-

2010) values of annual mean of highest temperature (c); the comparison between the reconstructed and observed values of annual mean of highest temperature from 1960-2010 (d)

\section{Discussion}

\section{Features of the $\delta^{13} C$}

The values of Tamarix leaf $\delta^{13} \mathrm{C}$ in the Minfeng sampling site are consistent with the results from Lop Nor (ranging from $-24.75 \%$ to $-22.38 \%$, with a mean of $-23.56 \%$, Xia et al., 2004) and Cele (ranging from -25.008\%o to $-23.138 \%$, with a mean of $-24.137 \%$, Zhang et al., 2017) regions. The $\delta^{13} \mathrm{C}$ signature is heavier than that of arid areas in northern China (Liu et al., 2014a) and broadly in accordance with the $\delta^{13} \mathrm{C}$ composition of $\mathrm{C}_{3}$ plants in arid environments. The slight difference between the range and average values of $\delta^{13} \mathrm{C}$ in the Minfeng site and values from the Lop Nor and Cele areas is likely due to the difference in climate conditions. Compared with the extremely arid Lop Nor 
area (the annual mean precipitation from 1960 to 2010 is $26.83 \mathrm{~mm}$ ), the climate of Minfeng sites (the annual mean precipitation from 1960 to 2010 is $29.45 \mathrm{~mm}$ ) is more humid relatively, leading to slightly lower $\delta^{13} \mathrm{C}$ values due to improved water conditions. This finding is similar to other studies (Liu et al., 1997; Sun et al., 2003; Yun, 2010; Zhao, 2012).

\section{Influence of temperature on Tamarix}

Temperature is one of the main factors affecting plant growth. The change in temperature may change the plant physiological responses. A declining temperature may result in a reduction in enzyme activity and photosynthetic rate, leading to decreased $\mathrm{CO}_{2}$ assimilation and a lower growth rate (Beerling, 1994). Several studies have observed an increase in $\Delta \delta^{13} \mathrm{C}$ with decreasing temperature (Mccarroll and Loader, 2004; Treydte et al., 2007; Wang et al., 2013). However, our results show a statistically significant negative correlation between temperature-related variables and $\delta^{13} \mathrm{C}$, and a significantly positive correlation between temperature and $\Delta \delta^{13} \mathrm{C}$. The $\delta^{13} \mathrm{C}$ and $\Delta \delta^{13} \mathrm{C}$ values are correlated with the annual mean of highest temperatures and the lowest temperature in each month. It appears that the higher temperature led to lower $\delta^{13} \mathrm{C}$ values and increased the carbon isotope fractionation. An opposite trend was observed in the Cele site (Zhang et al., 2017), showing some disagreement with our results (Wang et al., 2003; Liu et al., 2007; Shen and Chen, 2000; Zhao et al., 2011b).

\section{Influence of wind speed on Tamarix}

Few studies have investigated the effect of wind-related factors on plant growth. In this study, we found that the wind speed is positively related to $\delta^{13} \mathrm{C}$ values and negatively related to $\Delta \delta^{13} \mathrm{C}$ values in Tamarix growing seasons, and the correlations between the annual wind speed and $\Delta \delta^{13} \mathrm{C}$ values are more significant than those of $\delta^{13} \mathrm{C}$. The highest correlations are mostly in September, and the correlation between annual mean wind speed and $\Delta \delta^{13} \mathrm{C}$ is $-0.622(\mathrm{P}=0.001)$. These results suggest that the wind speed affects the Tamarix growth. The $\delta^{13} \mathrm{C}$ values are much heavier on higher wind speed conditions, and the effect of carbon isotope fractionation is weaker. This may due to the wind from desert is usually hot and dry, which may increase the transpiration and water consumption of Tamarix. Therefore, Tamarix may reduce stomatal opening status to mitigate water loss. Consequently, the photosynthesis is restrained and the $\delta^{13} \mathrm{C}$ value increases.

\section{Influence of precipitation and relative humidity on Tamarix}

Studies have reported the influence of water availability on plant carbon isotope fractionation, and a positive correlation between $\Delta \delta^{13} \mathrm{C}$ and water availability has been observed in most studies (e.g., Wang et al., 2005, 2008; Diefendorf et al., 2010; Kohn, 2010). In our study, a statistically poor negative relationship between the $\delta^{13} \mathrm{C}$ values and the precipitation occurs in January only, and a positive relationship between the $\Delta \delta^{13} \mathrm{C}$ values and the precipitation occurs in April only. We found the relative humidity has a significantly positive correlation with $\delta^{13} \mathrm{C}$ values and negative correlation with $\Delta \delta^{13} \mathrm{C}$ values in November. Different from our study, the $\delta^{13} \mathrm{C}$ values are correlated with precipitation only in February $(r=-0.522, p=0.012)$ in the Cele site (Zhang et al., 2017). 
These results suggest that the effect of local precipitation and relative humidity is relatively weak on the growth of Tamarix. This illustrates that the Tamarix growth has been adapted to the arid environment, mainly relies on the groundwater, the annual precipitation of $29.4 \mathrm{~mm}$ has little effect on Tamarix growth. Our preliminary analysis suggests that more precipitation in January and April, likely correlated with more snow, ice and rainfall on the mountains, may supply more available water for the growth of Tamarix, and consequently promote the photosynthetic rate and Tamarix growth.

\section{Temperature as the key growth-limiting factor}

The results of correlation analysis show that the effect of temperature-related variables on $\delta^{13} \mathrm{C}, \Delta \delta^{13} \mathrm{C}$ of Tamarix leaves is more significant than those of windrelated and precipitation-related variables. The $\delta^{13} \mathrm{C}$ and $\Delta \delta^{13} \mathrm{C}$ values are highly correlated with temperature-related variables: monthly lowest temperatures, the annual mean of lowest temperatures, the annual mean of highest temperatures and annual mean temperature. The number of wind-related variables is small and that of precipitationand humidity-related variables is few.

The PCA results show the temperature-related index is the major influence factor on the $\Delta \delta^{13} \mathrm{C}$. The first principal component explained about $51 \%$ of the standardized variance, whereas the second principal component accounted for $18 \%$. The first two components explained about $69 \%$ of the variance (Table 3). The first component showed strong positive loadings on 15 variables: annual mean temperature, annual mean of lowest temperature, annual mean of highest temperature and all monthly lowest temperatures. The second component shows the positive loadings the 9 wind-related variables only.

The influence of temperature on $\Delta \delta^{13} \mathrm{C}$ has been studied extensively (e.g., Körner et al., 1988, 1991; Morecroft and Woodward, 1996; Wang et al., 2008, 2013; Gebrekirstos et al., 2009; Diefendorf et al., 2010; Kohn, 2010). Our results indicate that the influence of temperature on the Tamarix growth is mainly on the carbon isotope fractionation. Thus, the temperature is identified as the key growth-limiting factor for the Tamarix growth. Similar results have also been observed by Liu et al. (2014a) and Xu et al. (2015).

\section{Analysis of reconstructed temperature}

The lowest temperature in June is significantly associated with the mean value of lowest temperatures in summer $(r=0.882, p=0.000)$, annual mean of lowest temperatures $(\mathrm{r}=0.810, \mathrm{p}=0.000)$ and the annual mean temperature $(\mathrm{r}=0.746, \mathrm{p}=$ 0.000). So, the reconstructed records of the lowest temperature in June and annual mean of highest temperature represent a long-term temperature fluctuation in the past 410 years (Fig. 3). The mean of LT Jun is $16.08{ }^{\circ} \mathrm{C}$ and that of AMHT is $20.58{ }^{\circ} \mathrm{C}$ for the full records. According to the departure from the average and the accumulated anomaly, the records can be further divided into the following four sub-periods:

The first period (1600-1685): The departure from normal value of the reconstructed $\mathrm{LT}_{\text {Jun }}$ and AMHT decreased year after year. The reconstructed $\mathrm{LT}_{\mathrm{Jun}}$ (the average value is $13.81{ }^{\circ} \mathrm{C}$ ) and AMHT (the average value is $19.85^{\circ} \mathrm{C}$ ) below averages. This period is defined as a history cold period.

The second period (1686-1910): The departure from normal value of the reconstructed $\mathrm{LT}_{\mathrm{Jun}}$ and AMHT rebounded from its lows (1685), and rose fast after 
1830. The mean of reconstructed $\mathrm{LT}_{\mathrm{Jun}}$ is $17.11^{\circ} \mathrm{C}$ before 1830 , and that rose to 17.37 ${ }^{\circ} \mathrm{C}$ in late 80 years. The mean of AMHT is $21.52{ }^{\circ} \mathrm{C}$. The reconstructed temperatures are warmer than averages. It is defined as the history warm period.

The third period (1911-1993): The departure from normal value of the reconstructed $\mathrm{LT}_{\mathrm{Jun}}$ and AMHT decreased rapidly till 1993. The mean of reconstructed $\mathrm{LT}_{\mathrm{Jun}}$ is 14.18 ${ }^{\circ} \mathrm{C}$ and that of AMHT is $19.44{ }^{\circ} \mathrm{C}$, those are cooler than averages until 1993. It is defined as modern cold period.

The fourth period (1994-2010): From 1994, the reconstructed temperatures turned warmer. The mean of reconstructed $\mathrm{LT}_{\mathrm{Jun}}$ is $18.91{ }^{\circ} \mathrm{C}$ and that of AMHT is $20.75{ }^{\circ} \mathrm{C}$. The $\mathrm{LT}_{\text {Jun }}$ rose more rapidly than AMHT. It is defined as modern warm period.

The mean of observed $\mathrm{LT}_{\mathrm{Jun}}$ is $15.14{ }^{\circ} \mathrm{C}$ and that of AMHT is $19.76^{\circ} \mathrm{C}$ from 1960 to 1993 , and those from 1994 to 2010 are $19.76^{\circ} \mathrm{C}$ and $20.42^{\circ} \mathrm{C}$, respectively. The trend of the constructed temperature is accord with those of the observed.

Our reconstructed records are broadly consistent with Zhao et al. (2016) that concluded that the past climate had experienced 4 stages based on TOC, TN and C/N analysis on the same sampling site. In particular, the two of our four periods, 1600-1690 (cool) and 1991-2010 (warm), are consistent with their study, but the other two, 16911900 (cool) and 1901-1990 (warm), have the opposite trends. The result shows that it had been warmer before 1912, and then turned cool. This is partly consistent with Zhao et al. (2015a) that reconstructed the climate record of the past 200 years using fossil pollen from the Andier ancient city; the history warm period (1685-1912) is roughly consistent with Guo et al. (2016) that reconstructed the past climate in Cele site based on fossil pollen data, and the history cold period (1600-1685) is consistent with Yao et al.'s (2001) study of the Guliya ice core. The discrepancies between these results may be caused by different materials, precision, or time scale.

\section{Sensitivity of the reconstructed records}

The $\delta^{13} \mathrm{C}$ and $\Delta \delta^{13} \mathrm{C}$ signature of Tamarix leaf are sensitive to the climate in the SMTD. The effects of climate on $\delta^{13} \mathrm{C}$ and $\Delta \delta^{13} \mathrm{C}$ in Minfeng sites are reversed with those in the Cele site and Lop Nor region except for the precipitation. The higher monthly lowest temperature and annual mean of highest temperature promote the Tamarix growth in the Minfeng site, whereas limit the Tamarix growth in the Cele site (Zhang et al., 2017). The opposite results suggest that the Tamarix growth is sensitive to the ecological environment. It may be caused by the difference in their geographical environment. With less population and no reservoir was constructed to adjust the runoff of the Andier river, the Minfeng oasis is smaller than the Cele oasis. Thus, the human interference is relatively lower in the Mingfeng site.

\section{Conclusions}

In this paper, we investigated the effects of the climate factors on $\delta^{13} \mathrm{C}$ and $\Delta \delta^{13} \mathrm{C}$ signatures in the Minfeng site. We found that the effect of temperature is most significant, can contribute to $50 \%$ of the carbon isotope fractionation, and is the key growth-limiting factor for the Tamarix growth. The wind speed is the second factor affecting on the Tamarix growth and it might significantly affect on plant growth in the growing seasons.

The reconstructed records in the lowest temperature in June and annual mean of highest temperature showed that the temperature fluctuated during the past 400 years. 
The lowest temperature in June rose more rapidly than the annual mean of highest temperatures in recent decades. Future studies are recommended to investigate the mechanism of the climate factors on the Tamarix growth and using multiple proxies to improve the understanding of the past climate change and predict how plants respond to climate change in the future.

Acknowledgements. This research was supported by the National Natural Science Foundation of China (Grant No. 41877448, U1303285) and the Construction Project of Key Disciplines in Colleges and Universities of Hebei Province.

\section{REFERENCES}

[1] Beerling, D. J. (1994): Predicting leaf gas exchange and $\delta^{13} \mathrm{C}$ responses to the past 30000 years of global environmental change. - New Phytologist 128(3): 425-433.

[2] Dawson, T. E., Siegwolf, R. T. W. (2007): Stable isotopes as indicators of ecological change. - Academic Press, San Diego.

[3] Diefendorf, A. F., Mueller, K. E., Wing, S. L. et al. (2010): Global patterns in leaf ${ }^{13} \mathrm{C}$ discrimination and implications for studies of past and future climate. - Proceedings of the National Academy of Sciences of the United States of America 107(13): 5738-5743.

[4] Dodd, J. P., Patterson, W. P., Holmden, C. et al. (2008): Robotic micromilling of treerings: A new tool for obtaining subseasonal environmental isotope records. - Chemical Geology 252(1-2): 21-30.

[5] Farquhar, G. D., Hubick, K. T., Condon, A. G. et al. (1989): Carbon isotope fractionation and plant water-use efficiency. - In: Rundel, P. W., Ehleringer, J. R., Nagy, K. A. (eds.) Stable isotopes in ecological research. Springer, New York, pp. 21-40.

[6] Farquhar, G. D., Richards, R. A. (1984): Isotopic composition of plant carbon correlates with water-use efficiency of wheat genotypes. - Aust. J. Plant Physiol. 11(6) 539-552.

[7] Farquhar, G. D., O’Leary, M. H., Berry, J. A. (1982): On the relationship between carbon isotope discrimination and the intercellular carbon dioxide concentration in leaves. Functional Plant Biology 9(2): 121-137.

[8] Friedli, H., Lotscher, H., Oeschger, H. et al. (1986): Ice-core record of the ${ }^{13} \mathrm{C} /{ }^{12} \mathrm{C}$ ratio of atmospheric $\mathrm{CO}_{2}$ in the past two centuries. - Nature 324: 237-238.

[9] Gebrekirstos, A., Worbes, M., Teketay, D. et al. (2009): Stable carbon isotope ratios in tree rings of co-occurring species from semi-arid tropics in Africa: Patterns and climatic signals. - Global \& Planetary Change 66(3-4): 253-260.

[10] Guo, F., Zhao, C., Zhao, Y. J. et al. (2016): Pollen assemblages of Tamarix cone sedimentary veins and environmental change in the southern margin of Taklimakan Desert for about the last 400 years. - Acta Palaeontologica Sinica 55(1): 136-144 (in Chinese).

[11] Kohn, M. J. (2010): Carbon isotope compositions of terrestrial $\mathrm{C}_{3}$ plants as indicators of (paleo) ecology and (paleo) climate. - Proc. Natl. Acad. Sci. U.S.A. 107: 19691-19695.

[12] Körner, C., Farquhar, G. D., Roksandic, Z. (1988): A global survey of carbon isotope discrimination in plants from high altitude. - Oecologia 74: 623-632.

[13] Körner, C., Farquhar, G. D., Wong, S. C. (1991): Carbon isotope discrimination by plants follows latitudinal and altitudinal trends. - Oecologia 88: 30-40.

[14] Leavitt, S. W., Long, A. 1989. The atmospheric Delta-C-13 record as derived from 56 Pinyon trees at 14 sites in the southwest United States. - Radiocarbon 31(3): 469-474.

[15] Liu, G. S., Qi, C. M., Lin, X. Y. et al. (1997): Reflection of surface runoff variation by tree-ring in its drainage area. - Journal of Changchun University of Earth Sciences 3: 333-336 (in Chinese). 
[16] Liu, X., Su, Q., Li, C., Zhang, Y. et al. (2014a): Responses of carbon isotope ratios of $\mathrm{C}_{3}$ herbs to humidity index in Northern China. - Turkish Journal of Earth Sciences 23(1): $100-111$.

[17] Liu, X. H., Shao, X. M., Wang, L. L. et al. (2007): Climatic significance of the stable carbon isotope composition of tree-ring cellulose: Comparison of Chinese hemlock (Tsuga chinensis Pritz) and alpine pine (Pinus densata Mast) in a temperate-moist region of China. - Science in China (D) 7: 1076-1085.

[18] Liu, X. Z., Zhang, Y., Su, Q. et al. (2014b): Research progress in responses of modern terrestrial plant carbon isotope composition to climate change. - Advances in Earth Science 12: 1341-1354 (in Chinese).

[19] Loader, N. J., Mccarroll, D., Gagen, M. et al. (2007): Extracting climatic information from stable isotopes in tree rings. - Terrestrial Ecology 1(1): 25-48.

[20] Mccarroll, D., Loader, N. J. (2004): Stable isotopes in tree rings. - Quaternary Science Reviews 23(7): 771-801.

[21] Morecroft, M. D., Woodward, F. I. (1996): Experiments on the causes of altitudinal differences in leaf nutrient contents, age and ${ }^{13} \mathrm{C}$ of Alchemilla alpine. - New Phytol. 134: 471-479.

[22] Ren, S. J., Yu, G. R. (2011): Carbon isotope composition $\left(\delta^{13} \mathrm{C}\right)$ of $\mathrm{C}_{3}$ plants and water use efficiency in china. - Chinese Journal of Plant Ecology 16(5) (in Chinese).

[23] Saurer, M., Siegenthaler, U., Schweingruber, F. (1995): The climate-carbon isotope relationship in tree rings and the significance of site conditions. - Tellus Series BChemical \& Physical Meteorology 47(3): 320-330.

[24] Seibt, U., Rajabi, A., Griffiths, H. et al. (2008): Carbon isotopes and water use efficiency: sense and sensitivity. - Oecologia 155: 441-454.

[25] Shen, J., Chen, Y. F. (2000): The climatic reconstruction from the tree-ring $\delta^{13} \mathrm{C}$ values of Cedrus deodara (Roxb.) Loud. during the past 20 years in Nanjing. - Journal of Plant Resources and Environment 3: 34-37 (in Chinese).

[26] Sun, B. N., Dilcher, D. L., Beerling, D. J. et al. (2003): Variation in Ginkgo Biloba L leaf characters across a climatic gradient in China. - PNAS 12: 7141-7146.

[27] Sun, Z. Y. (2013): The climate change revealed by the $\delta^{13} \mathrm{C}$ values of Tamarix cone sedimentary veins in the south region of Taklimakan Desert. - Hebei Normal University, Shijiazhuang (in Chinese).

[28] Sun, Z. Y., Zhang, J., Zeng, J. et al. (2013): The modern climate change revealed by the sedimentary veins of Tamarix dune in Lop Nor region. - Journal of Arid Land Resources and Environment 27(7): 127-133 (in Chinese).

[29] Treydte, K., Frank, D., Esper, J. et al. (2007): Signal strength and climate calibration of a European tree-ring isotope network. - Geophys. Res. Lett. 34: 1-6.

[30] Wang, G., Han, J. M., Liu, D. S. (2003): The carbon isotope composition of $\mathrm{C}_{3}$ herbaceous plants in loess area of northern China. - Science in China (D) 10: 1070-1076.

[31] Wang, G., Han, J., Zhou, L. et al. (2005): Carbon isotope ratios of plants and occurrences of $\mathrm{C}_{4}$ species under different soil moisture regimes in arid region of Northwest China. Physiologia Plantarum 125(1): 74-81.

[32] Wang, G., Feng, X., Han, J. et al. (2008): Paleovegetation reconstruction using $\delta^{13} \mathrm{C}$ of soil organic matter. - Biogeosciences 5(2): 1325-1337.

[33] Wang, G., Li, J., Liu, X. et al. (2013): Variations in carbon isotope ratios of plants across a temperature gradient along the $400 \mathrm{~mm}$ isoline of mean annual precipitation in north China and their relevance to paleovegetation reconstruction. - Quaternary Science Reviews 63(1): 83-90.

[34] Werner, C., Schnyder, H., Cuntz, M. et al. (2012): Progress and challenges in using stable isotopes to trace plant carbon and water relations across scales. - Biogeosciences 9(8): 3083-3111.

[35] Xia, X. C., Zhao, Y. J., Wang, F. B. et al. (2004): Stratification features of Tamarix cone and its possible age significance. - Chinese Science Bulletin 49(14): 1539-1540. 
[36] Xu, M., Wang, G., Li, X. et al. (2015): The key factor limiting plant growth in cold and humid alpine areas also plays a dominant role in plant carbon isotope discrimination. Frontiers in Plant Science (6): 1-9.

[37] Yao, T. D., Yang, M. X., Kang, X. C. (2001): Comparative study of the climate changes in the past 2000 years by using ice core and tree ring records. - Quaternary Sciences 21(6): 514-519.

[38] Yun, H. B. (2010): Research on the seasonal characteristics of $\delta^{13} \mathrm{C}, \delta \mathrm{N}$ and Nonstructural carbohydrate of main plants in different ecosystems in the inland of QinghaiTibet Plateau. - Northwest Normal University, Xian (in Chinese).

[39] Zhang, Z. G., Fang, Y., Li, L. et al. (2017): The Reconstruction of the paleotemperature in the southern margin of the Taklimakan Desert based on carbon isotope discrimination of Tamarix leaves. - Applied Ecology and Environmental Research 15(4): 561-570.

[40] Zhao, C., Guo, F., Zhao, Y. J. et al. (2015a): Pollen assemblages of Tamarix cone and environmental change in Andier ancient city region during the recent 200 years. - Journal of Arid Land Resources and Environment 29(11): 158-163 (in Chinese).

[41] Zhao, Y. (2012): Morphological and physiological responses of Populus euphratica leaf to groundwater table variations in the lower reaches of Heihe river. - Lanzhou University, Lanzhou (in Chinese).

[42] Zhao, Y. J., Wang, X. Y., Xia, X. C. et al. (2011b): The $\delta^{13} \mathrm{C}$ sequence of Tamarix cone sedimentary veins and climate reconstruction during last 160 years in Lop Nur region, Xinjiang, China. - Quaternary Sciences 31(1): 130-136 (in Chinese).

[43] Zhao, Y. J., Li, X. F., Xia, X. C. et al. (2011a): C and N contents in organic matter of Tamarix dune sedimentary veins and environmental change in Lop Nur region. - Journal of Arid Land Resources and Environment 25(4): 149-154 (in Chinese).

[44] Zhao, Y. J., Liu, H., Che, G. H. et al. (2015b): On age sequence establishment method of Tamarix cone sedimentary veins in desert region. - Arid Zone Research 32(4): 810-817 (in Chinese).

[45] Zhao, Y. J., Che, G. H., Liu, H. et al. (2016): C and N content in organic matter of Tamarix cone and climatic and environmental change in southern region of Taklimakan Desert. - Arid Land Geography 39(3): 461-467 (in Chinese). 